\title{
(2) OPEN ACCESS \\ Association between community-level social capital and frailty onset among older adults: a multilevel longitudinal study from the Japan Gerontological Evaluation Study (JAGES)
}

\author{
Taiji Noguchi (1) ${ }^{1,2}$ Chiyoe Murata, ${ }^{1,3}$ Takahiro Hayashi, ${ }^{4}$ Ryota Watanabe, ${ }^{5,6}$ \\ Masashige Saito, ${ }^{7}$ Masayo Kojima, ${ }^{5}$ Katsunori Kondo, ${ }^{6,8}$ Tami Saito $^{1}$
}

\section{- Additional online} supplemental material is published online only. To view, please visit the journal online (http://dx.doi.org/10.1136/ jech-2021-217211)

For numbered affiliations see end of article.

\section{Correspondence to}

Dr Taiji Noguchi, Department of Social Science, Research Institute, National Center for Geriatrics and Gerontology, Obu, Aichi, Japan; noguchi.taiji0415@gmail.com

Received 7 May 2021 Accepted 10 July 2021 Published Online First 2 August 2021

\section{Check for updates}

(c) Author(s) (or their employer(s)) 2022. Re-use permitted under CC BY-NC. No commercial re-use. See rights and permissions. Published by BMJ.

To cite: Noguchi T,

Murata C, Hayashi T, et al. J

Epidemiol Community Health

2022:76:182-189.

\begin{abstract}
Background Little is known about the prospective association between community-level social capital and individual-level frailty onset. Therefore, this study aimed to examine the impact of community-level social capital on frailty onset among older adults using 3-year longitudinal data.
\end{abstract}

Methods This prospective cohort study recruited noninstitutionalised older adults from the Japan Gerontological Evaluation Study, established in 2013 and robust older adults were followed up for 3 years. We assessed three aspects of community-level social capital (civic participation, social cohesion and reciprocity), and employed a multilevel logistic regression analysis; frailty was evaluated using the Kihon Checklist questionnaire, which has been widely used as a screening tool for frailty in Japan.

Results In total, 21940 older adults (from 384 communities) who were robust at baseline (2013) completed the follow-up survey (2016). Participants' mean age (SD) was 71.8 (4.9) years, and $51.2 \%$ were female. In the follow-up period, frailty onset occurred in 622 participants (2.8\%). Regarding community-level social capital variables, civic participation was inversely associated with frailty onset (OR=0.94, 95\% Cl 0.90 to $0.97, p=0.001$ ), after adjusting for individuallevel and community-level covariates. The potential intermediate factors of individual social relationships and health behaviours did not largely change the results. This association was found regardless of individual socioeconomic status.

Conclusions Living in a community with rich civic participation, such as engagement in social activities, was associated with lower frailty onset among older adults. Community development that fosters social participation is essential for frailty prevention.

\section{INTRODUCTION}

The proportion of older adults is increasing worldwide. ${ }^{1}$ Japan has the highest life expectancy and the most rapidly ageing society. ${ }^{2}$ Such a populational increase denotes higher healthcare, social security costs and societal challenges. Thus, facilitating healthy ageing (eg, by maintaining functional capacity) is crucial. ${ }^{3}$ One measure in this regard is the preventive aspect of dealing with frailty.

Frailty is a state of increased vulnerability to poor resolution of homeostasis following stress, regarded as an age-related physiological syndrome,${ }^{45}$ which evokes greater risks for older adults regarding adverse health outcomes, such as institutionalisation, hospitalisation, functional disability and mortality. ${ }^{6-9}$ While the definition is insufficiently conclusive, frailty is also characterised as an unstable state in which even very small stressors could lead to major deterioration and functional dependence, and is therefore regarded as an intermediate condition between being healthy and ill/ disabled. ${ }^{45}$ Therefore, frailty prevention is key for older adults to achieve healthy ageing. ${ }^{10}$

According to the conceptual model, frailty is determined by multidimensional aspects, comprising physical, psychological, social and even environmental domains. ${ }^{11-13}$ Focusing only on older adults' physical problems when dealing with frailty may evoke fragmented care. ${ }^{14}$ However, little is known about the effects of environmental factors, such as poorquality housing, community environments and social network changes, on frailty. The environment that older adults inhabit can compensate for their intrinsic capacity decline and help maintain their functional abilities, which is essential for healthy ageing. ${ }^{15}$ Hence, examining the social-environmental factors of frailty seems important for its prevention.

One factor is social capital, which has been extensively examined, including its relation to health. ${ }^{16}$ There are several concepts of social capital. For instance, Putnam et al define social capital as 'features of social organisation, such as trust, norms and networks that can improve the efficiency of society by facilitating coordinated actions'. ${ }^{17}$ Saito et $a l^{18}$ developed a community-level social capital scale based on the definitions of Putnam et al, ${ }^{17}$ Coleman ${ }^{19}$ and Kawachi et al. ${ }^{20}$ This scale was developed for community assessment, and its concurrent validity with health indicators has been confirmed. ${ }^{18}$ This scale also consists of 'structural' (eg, social network density or civic engagement patterns) and 'cognitive' (eg, level of trust perception and norms of reciprocity between individuals) aspects of social capital. ${ }^{16} 21$ The present study focused on community-level social capital from these two aspects using this scale.

Community social capital was shown to exert a contextual effect on individual health through the diffusion of knowledge on health promotion; maintenance of healthy behavioural norms through 
informal social control; promotion of access to local services and amenities; and psychological processes that provide emotional support and mutual respect. ${ }^{22}$ Compared with conventional studies using ecological-level or individual-level approaches, a multilevel analytical approach that can statistically differentiate between group-level and individual-level associations can help in better understanding the collective/contextual influences of social capital. ${ }^{16}$

Although studies using multilevel analyses have revealed the positive association of community-level social capital with various health outcomes, including mortality and disability, ${ }^{23-26}$ only two studies have reported the effects of social capital on frailty. In China, a cross-sectional study found no significant association between community-level social capital and individual frailty. ${ }^{27}$ Meanwhile, in Japan, a cross-sectional study examining the effect of three forms of social capital (civic participation, social cohesion and reciprocity) reported an inverse association between higher community-level civic participation and the likelihood of individual frailty. ${ }^{28}$ However, there is lack of evidence in longitudinal studies, and thus temporal relationships between the two variables need to be clarified.

We examined the association between community-level social capital and frailty onset among older adults in Japan, using multilevel analytical modelling and a 3-year longitudinal study design.

\section{METHODS}

\section{Participants}

In this prospective longitudinal study, we obtained panel data from the Japan Gerontological Evaluation Study (JAGES), an ongoing cohort study among non-institutionalised and functionally independent older adults aged 65 years and above in Japan. ${ }^{29}$ The JAGES includes only older adults who are ineligible for public long-term care insurance benefits.

Figure 1 shows the sample selection flow chart. A baseline survey was conducted between October and December 2013; self-reported questionnaires were mailed to eligible residents in 30 municipalities. Random sampling methods were used in 17 large municipalities; in the other 13 , all eligible residents could participate. Of the 193694 people invited, 137736 returned the questionnaires (response rate: 71.1\%). We excluded 7996 individuals whose age and gender could not be confirmed (valid response rate: $67.0 \%$ ). We also excluded 3066 individuals in 86 community areas with $<50$ respondents to avoid non-precise values from the sample size and 28786 respondents with unknown area of residence; thus, 97888 respondents from 478 communities were aggregated by school districts to evaluate community-level social capital. ${ }^{18}$ We selected school districts as a community unit because, in Japan, school districts are the geographical unit that older adults can easily travel by foot or bicycle within and are a valuable unit for considering local public health activities.

We excluded 3222 respondents with limitations in performing basic activities of daily living (BADL), 4228 respondents with missing responses on BADL items, 638 respondents with selfreported dementia or Parkinson's disease, 5099 respondents with missing information about their present illness, 31789 respondents with prefrailty or frailty assessed using the Kihon Checklist (KCL), ${ }^{30-32}$ and 17560 respondents with incomplete responses to the KCL items.

Baseline survey, 2013

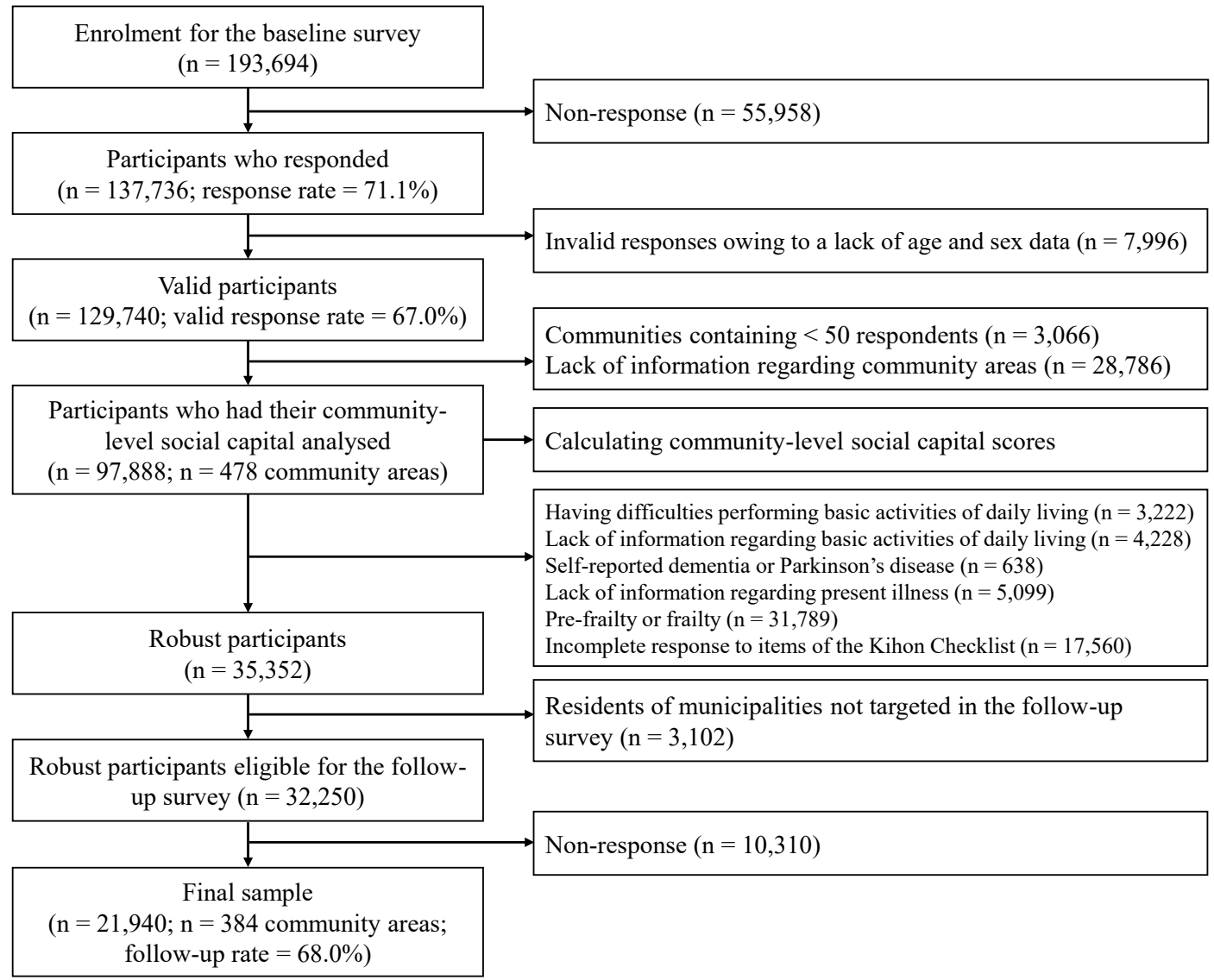

Figure 1 Sample selection flow chart. 
Then, 32250 robust older adults were followed up to check for new occurrences of frailty, excluding 3102 individuals whose municipalities were not targeted by the follow-up survey owing to the local governments' refusal to cooperate. The follow-up was conducted during October-November 2016. Finally, 21940 participants (from 384 districts) who completed the survey were included in the analysis (follow-up rate: $68.0 \%$ ).

\section{Frailty}

Frailty was defined using the KCL developed by the Japanese Ministry of Health, Labour and Welfare, which is widely used for frailty screening in Japan. ${ }^{30}$ The KCL is a simple yes/no questionnaire that assesses multiple aspects of daily living functions, such as instrumental ADL, social living, motor, oral and cognitive function, nutrition state, homebound status and mood. ${ }^{30}$ Responding 'yes' to any item counts as a point (score range: 0-25), with higher scores indicating frailty tendency. Based on previous studies, ${ }^{28}{ }^{29}$ we classified participants into three groups: robust (0-3 points), prefrailty (4-7) and frailty $(\geq 8)$.

The JAGES uses a slightly modified version of this tool (online supplemental table 1 and text 1). We used the scoring system established in a prior study that used the same modified version as the JAGES. ${ }^{28}$ We followed up participants who were robust at baseline for 3 years.

\section{Community-level social capital}

Based on prior research, ${ }^{18}$ at baseline, we assessed the three components of community-level social capital: civic participation, social cohesion and reciprocity; civic participation is regarded as reflecting the structural aspects of social capital, and social cohesion and reciprocity as reflecting the cognitive aspects. $^{33}{ }^{34}$ Individual-level data were aggregated by school districts.

Civic participation was assessed by the percentage of individual participation in a volunteer group, sports group, hobby activity, study or culture group, and skill teaching in each community. Each of the five items were assigned between 0 and 100 points.

Social cohesion was assessed by the percentage of 'very' or 'moderately' answers (response scale: 'very', 'moderately', 'neutral', 'slightly' or 'not at all') to three items: general trust ('In general, do you think that people living in your area can be trusted?'), perception of others' intention to help ('Do you think people living in your area try to help others in most situations?') and attachment to the residential area ('How attached are you to the area where you live?'). Each of the three items was assigned between 0 and 100 points.

Reciprocity was assessed by the percentage of 'yes' answers to three items: emotional support receival ('Do you have someone who listens to your concerns and complaints?'), emotional support provision ('Do you listen to the concerns and complaints of other(s)?'), and instrumental support receival ('Do you have someone who looks after you when you are sick and confined to bed?'). Each of the three items were assigned between 0 and 100 points.

We conducted a factor analysis using a total of 11 items with aggregated individual-level data and used factor scores calculated as community-level social capital scores in each school district (online supplemental table 2).

\section{Other variables}

We used individual sociodemographic characteristics and health status, and community-level characteristics as covariates.

Individual-level factors included age (65-69, 70-74, 75-79, $80-84$ or $\geq 85$ years), gender, living arrangement (living with others or living alone), marital status (unmarried or married), education ( $<10,10-12$ or $\geq 13$ years), equivalent income (by tertiles, calculated by dividing the income of each household by the square root of the number of family members), self-rated health (good or poor), present illnesses (none, one, or two or more of cancer, heart disease, stroke, respiratory disease, musculoskeletal disease, hypertension, dyslipidaemia and diabetes), alcohol consumption (never/past or currently), smoking history (never/past or currently) and walking time $(<60$ or $\geq 60 \mathrm{~min} /$ day).

Individual social relationships were assessed using four variables: the frequency of contact with friends (more than or less than once a week), participation in community groups (no $(0)$ or yes ( $\geq 1$ point); this was measured using responses to the aforementioned five groups for community-level civic participation, with a score range of $0-5$ ), perception of community social cohesion (no ( 0 ) or yes ( $\geq 1$ point); measured using responses to the aforementioned three items for community-level social cohesion, with a score range of $0-3$ ), and social support (low $(0-2)$ or high (3 points)); measured using responses to the aforementioned three items for community-level reciprocity, with a score range of $0-3$ ).

Community-level variables included urbanisation (defined, based on population density, as follows: rural, $<1000$ people/ $\mathrm{km}^{2}$; suburban, 1000-1500 and urban, $\geq 1500$ ), ageing rate (the proportion of people aged $\geq 65$ years; divided into tertiles) and rate of low-level education (the proportion of people in each district who had graduated only from junior high school; divided into tertiles). Information on these variables was obtained from the 2013 Japanese Census.

\section{Statistical analysis}

The data included individuals (first level) nested in community districts (second level). The multilevel analysis framework assumes that individual outcomes are partly dependent on the districts where individuals live; the variation in outcomes across districts (random effects); and the effects of community-level variables on the outcomes, adjusting for individual characteristics (fixed effects).

Accordingly, we performed a multilevel logistic regression analysis to calculate ORs and 95\% CIs for frailty onset. ORs were estimated based on a change of 10 percentage points in community-level social capital scores. First, we used the null model to assess whether frailty onset varied across districts. In model 1, we examined the association between communitylevel social capital and frailty onset, without adjusting for covariates. In model 2, we included age, gender, living arrangement, marital status, education, equivalent income, self-rated health, present illness and community-level variables. In model 3 , we added the variables of individual social relationships and in model 4, we included additional health behaviours (alcohol consumption, smoking history and walking time) to examine if these factors attenuate the association between communitylevel social capital and frailty onset. Based on the randomeffects variance, we calculated the median OR to examine the unexplained heterogeneity between communities (a median OR further away from 1 indicates a strong difference between communities). ${ }^{35}$ 
Table 1 Participants' characteristics

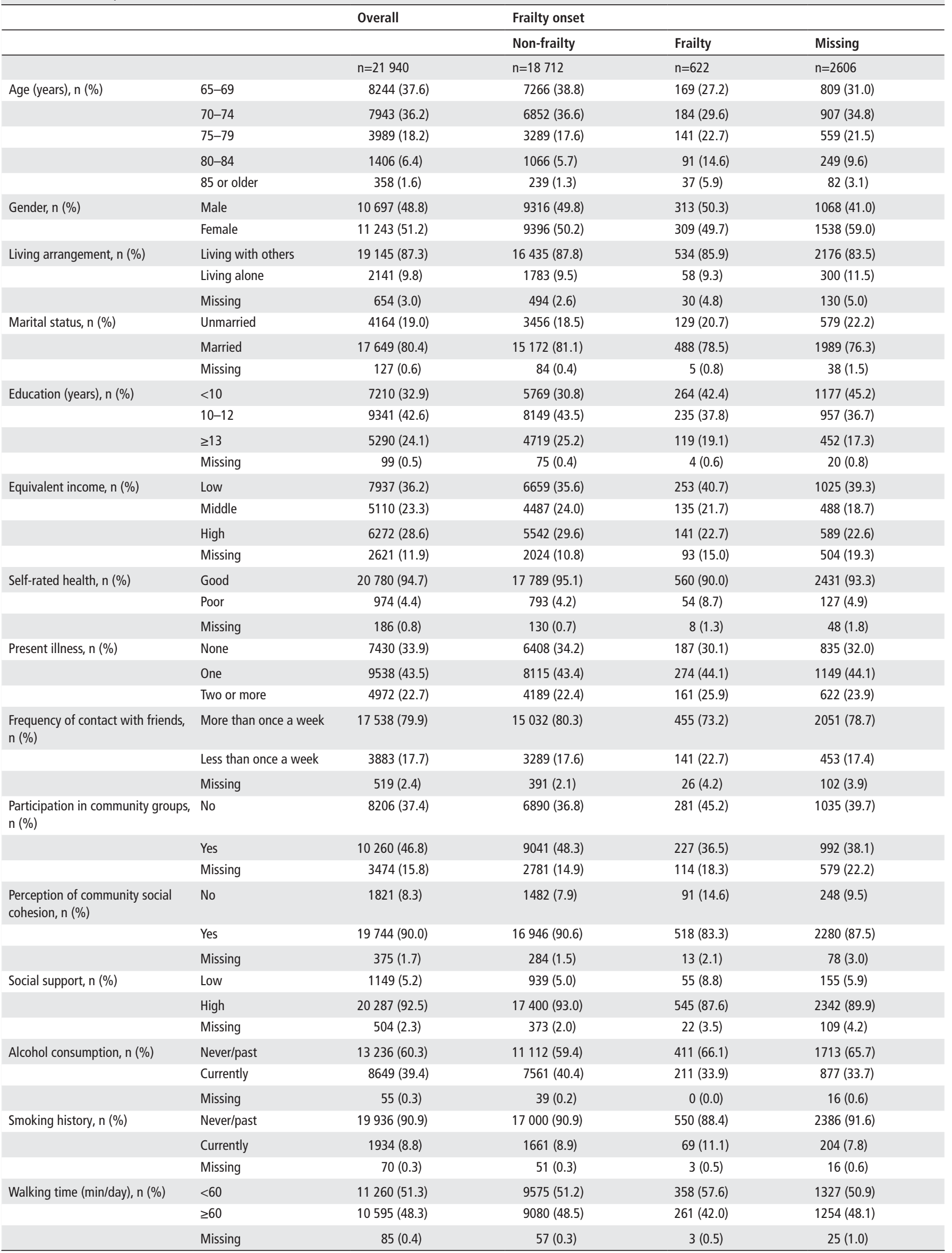


Table 2 Characteristics of the communities $(n=384)$

\begin{tabular}{|c|c|c|c|}
\hline & $\mathbf{n}$ & Mean (SD) & $\begin{array}{l}\text { Minimum, } \\
\text { maximum }\end{array}$ \\
\hline \multicolumn{4}{|c|}{ Community-level social capital* } \\
\hline Civic participation & 384 & $0.15(0.90)$ & $-2.57,3.51$ \\
\hline Social cohesion & 384 & $-0.09(0.95)$ & $-3.11,2.88$ \\
\hline Reciprocity & 384 & $-0.02(0.87)$ & $-3.74,2.11$ \\
\hline \multicolumn{4}{|l|}{ Urbanisationt } \\
\hline Rural & 58 & - & - \\
\hline Suburban & 40 & - & - \\
\hline Urban & 286 & - & - \\
\hline \multicolumn{4}{|l|}{ Ageing rateł } \\
\hline Low & 134 & - & - \\
\hline Middle & 129 & - & - \\
\hline High & 121 & - & - \\
\hline \multicolumn{4}{|c|}{ Rate of low-level education§ } \\
\hline Low & 142 & - & - \\
\hline Middle & 117 & - & - \\
\hline High & 125 & - & - \\
\hline
\end{tabular}

*Factor score.

†Defined by population density (persons $/ \mathrm{km}^{2}$ in an inhabitable area): rural, $<1000$; suburban, $1000-1500$ and urban, $\geq 1500$ persons $/ \mathrm{km}^{2}$.

‡Defined by the percentage of people aged 65 years or older: low, $17.3 \%-19.8 \%$; middle, $19.9 \%-21.8 \%$; high, $22.0 \%-47.6 \%$.

$\S$ Defined by the percentage of people who had graduated only from junior high school: low, $5.2 \%-10.1 \%$; middle, $11.0 \%-16.4 \%$; high, $16.4 \%-38.0 \%$.

To confirm the results' robustness against potential misclassification of frailty onset, we performed a sensitivity analysis using modified frailty diagnostic criteria (online supplemental table 1 and text 1 ). We also analysed the data using prefrailty and frailty onset as the combined outcome. Additionally, we conducted stratified analyses for the following variables: age (65-74 or $\geq 75$ years), gender, education (low: $<10$ or high: $\geq 10$ years) and equivalent income (divided into two by median (low or high) value).

To mitigate potential biases caused by missing information, we used the multiple imputation approach, under the missing at random assumption. We generated 20 imputed datasets using the multiple imputation by chained equations procedure and pooled the results using the standard Rubin's rule. ${ }^{36}$

Significance was set at $\mathrm{p}<0.05$. Statistical analyses were conducted using R software (V.3.6.3 for Windows).

\section{RESULTS}

We analysed data from 21940 robust participants. Table 1 shows the participants' characteristics at baseline. Participants' mean age was 71.8 years $(\mathrm{SD}=4.9)$, and $51.2 \%$ were female. In the follow-up period, $622(2.8 \%)$ had experienced frailty onset. Participants with frailty onset were more likely to: be older, have low education, have low equivalent income, have low social support, have poorer self-rated health, have shorter daily walking time, less frequently contact their friends, not participate in community groups, not perceive community social cohesion and not consume alcohol.

Table 2 shows the characteristics of the 384 communities analysed. The average frailty onset was $2.6 \%$ (minimum: $0.0 \%$; maximum: $33.3 \%$ ). The mean (SD) of community-level social capital scores were $0.15(0.90),-0.09(0.95)$ and -0.02 (0.87) for civic participation, social cohesion and reciprocity, respectively.
Table 3 shows the association between community-level social capital and frailty onset (all information about the results is provided in online supplemental table 3). Higher community civic participation demonstrated a significant association with a lower risk for frailty onset, after adjusting for individual-level and community-level covariates (model 2: OR (95\% CI) 0.94 (0.90 to 0.97$), p=0.001)$. This association remained largely unchanged after incorporating the variables of individual social relationships (model 3: OR=0.94 (95\% CI 0.91 to 0.98), $\mathrm{p}=0.003)$ and health behaviours (model $4: \mathrm{OR}=0.94(95 \% \mathrm{CI}$ 0.91 to 0.98$), p=0.003$ ) into the analytical model. The sensitivity analysis using the modified frailty criteria (online supplemental table 4 ) and prefrailty and frailty onset as the combined outcome (online supplemental table 5) showed similar trends to the main results. We also found similar results in the completecase analysis (online supplemental table 6).

Table 4 shows the results of the stratified analyses. Communitylevel civic participation and frailty onset showed an inverse association at all strata; that is, there were no interactions (age, $p=0.344$; gender, $p=0.399$; education, $p=0.740$; equivalent income, $\mathrm{p}=0.614$ ).

\section{Discussion}

To the best of our knowledge, this was the first study to examine the prospective association between community-level social capital and frailty onset in older adults. Specifically, living in communities with higher civic participation was associated with a lower frailty onset within 3 years. Our findings suggest that community development with rich social participation can help prevent frailty among older adults.

In a previous study in China, neighbourhood-level social cohesion and social participation were both not found to be associated with frailty. ${ }^{27}$ However, in that study, the sample sizes of individuals and communities investigated were somewhat smaller, thereby leading to potential non-detection of its effects. Meanwhile, in Japan, a nationwide study suggested an inverse association between high community-level civic participation and the likelihood of individual-level frailty ${ }^{28}$; our results supported this finding and revealed the longitudinal association between community-level civic participation and frailty.

Several longitudinal studies have suggested the protective effects of community-level civic participation on health outcomes related to frailty (eg, oral health and depression). ${ }^{3738}$ Thus, living in a community with rich civic participation could prevent multiple aspects of frailty. Since social-environmental factors that promote social activities are key to healthy ageing, ${ }^{15}$ fostering community-level social capital may be essential for frailty prevention.

Our results show that each $10 \%$ points increase in communitylevel civic participation reduces frailty onset by approximately $6 \%$. The effect size is not large, but it may be appropriate as an individual health effect caused by social-environmental factors. Rather, because social-environmental factors can cause widespread exposure to the residents in the area, social capital might be an important intervention target in public health to prevent frailty among older adults.

The association between community-level civic participation and frailty onset remained largely unchanged after including individual social relationships and health behaviours into analytical models. Although we hypothesised that the contextual effects of community-level social capital on frailty prevention are mediated by the promotion of individual social relationships 
Table 3 Association between community-level social capital and frailty onset, based on a multilevel logistic regression analysis with multiple imputation approach

\begin{tabular}{|c|c|c|c|c|c|c|c|c|c|c|}
\hline & & \multirow[t]{2}{*}{ Null model } & \multicolumn{2}{|l|}{ Model 1} & \multicolumn{2}{|l|}{ Model 2} & \multicolumn{2}{|l|}{ Model 3} & \multicolumn{2}{|l|}{ Model 4} \\
\hline & & & OR $(95 \% \mathrm{Cl})$ & $P$ value & OR $(95 \% \mathrm{Cl})$ & $P$ value & OR $(95 \% \mathrm{Cl})$ & $P$ value & OR $(95 \% \mathrm{Cl})$ & $P$ value \\
\hline \multicolumn{11}{|l|}{ Fixed effects } \\
\hline \multicolumn{11}{|l|}{ Community-level variables } \\
\hline \multicolumn{11}{|l|}{ Social capital* } \\
\hline Civic participation & & & 0.91 (0.88 to 0.94$)$ & $<0.001$ & $0.94(0.90$ to 0.97$)$ & 0.001 & $0.94(0.91$ to 0.98$)$ & 0.003 & $0.94(0.91$ to 0.98$)$ & 0.003 \\
\hline Social cohesion & & & 1.01 (0.98 to 1.05$)$ & 0.462 & $0.98(0.94$ to 1.02$)$ & 0.295 & $0.99(0.95$ to 1.03$)$ & 0.483 & 0.99 (0.95 to 1.03$)$ & 0.498 \\
\hline Reciprocity & & & 1.02 (0.98 to 1.06$)$ & 0.277 & 1.03 (0.99 to 1.07$)$ & 0.093 & 1.04 (1.00 to 1.08$)$ & 0.075 & 1.04 (1.00 to 1.08$)$ & 0.073 \\
\hline \multicolumn{11}{|l|}{ Individual-level variables } \\
\hline $\begin{array}{l}\text { Frequency of contact with } \\
\text { friends (ref: more than once } \\
\text { a week) }\end{array}$ & $\begin{array}{l}\text { Less than } \\
\text { once a week }\end{array}$ & & & & & & 1.19 (1.00 to 1.41$)$ & 0.051 & 1.18 (0.99 to 1.41$)$ & 0.060 \\
\hline $\begin{array}{l}\text { Participation in community } \\
\text { groups (ref: no) }\end{array}$ & Yes & & & & & & 0.74 (0.64 to 0.86$)$ & $<0.001$ & 0.75 (0.65 to 0.88$)$ & $<0.001$ \\
\hline $\begin{array}{l}\text { Perception of community } \\
\text { social cohesion (ref: no) }\end{array}$ & Yes & & & & & & 0.59 (0.47 to 0.73$)$ & $<0.001$ & 0.59 (0.48 to 0.74$)$ & $<0.001$ \\
\hline Social support (ref: low) & High & & & & & & $0.59(0.46$ to 0.75$)$ & $<0.001$ & 0.59 (0.46 to 0.76$)$ & $<0.001$ \\
\hline $\begin{array}{l}\text { Alcohol consumption (ref: } \\
\text { never/past) }\end{array}$ & Currently & & & & & & & & 0.88 (0.75 to 1.04$)$ & 0.136 \\
\hline $\begin{array}{l}\text { Smoking history (ref: never/ } \\
\text { past) }\end{array}$ & Currently & & & & & & & & 1.35 (1.06 to 1.70$)$ & 0.013 \\
\hline $\begin{array}{l}\text { Walking time (ref: }<60 \mathrm{~min} / \\
\text { day) }\end{array}$ & $\geq 60$ & & & & & & & & 0.85 (0.75 to 0.98$)$ & 0.020 \\
\hline \multicolumn{11}{|l|}{ Random effects } \\
\hline Community-level variance & & 0.194 & 0.147 & & 0.063 & & 0.066 & & 0.064 & \\
\hline Median OR & & 1.52 & 1.44 & & 1.27 & & 1.28 & & 1.27 & \\
\hline
\end{tabular}

Model 1 was a crude model; model 2 was adjusted for age, gender, living arrangement, marital status, education, equivalent income, self-rated health, present illness and community-level characteristics (urbanisation, ageing rate and rate of low-level education); model 3 was adjusted for frequency of contact with friends, participation in community groups, perception of community social cohesion and social support in addition to model 2 covariates; model 4 was adjusted for alcohol consumption, smoking history and walking time in addition to model 3 covariates. All information about the results is provided in online supplemental table 3.

*Estimation per 10 percentage points.

or health behaviours, these mediations were hardly observed. The contextual effects of group-level social capital on health are considered to involve mechanisms such as social contagion (dissemination of health information and behaviour), informal social control (loose management of unhealthy behaviour) or collective efficacy (mobilisation of groups for the development of health-related facilities or systems). ${ }^{22}$ Alternatively, in terms of network nature, rich civic participation in the communities could loosely connect diverse people (bridging) or promote the links between people from different social classes (linking). ${ }^{1621}$ Meanwhile, because several clinical and lifestyle factors, such as nutritional status, sedentary behaviour and polypharmacy, ${ }^{39}$ are considered risk factors for frailty, these pathways might also be involved. Therefore, further investigations on the mechanisms and nature of the links between community-level social capital and frailty are needed.

The stratified analyses of age, gender, education, and equivalent income showed that the association between

Table 4 Stratified analyses for the association between community-level social capital and frailty onset by individual demographic factors based on a multilevel logistic regression analysis with multiple imputation approach

\begin{tabular}{|c|c|c|c|c|c|c|c|}
\hline & & \multicolumn{6}{|c|}{ Community-level social capital* } \\
\hline & & Civic participation & \multirow[b]{2}{*}{$P$ value } & \multicolumn{2}{|l|}{ Social cohesion } & \multicolumn{2}{|l|}{ Reciprocity } \\
\hline & & & & OR $(95 \% \mathrm{Cl}) \dagger$ & $P$ value & OR $(95 \% \mathrm{Cl}) \dagger$ & $P$ value \\
\hline \multirow[t]{2}{*}{ Age } & $65-74$ years & 0.92 (0.87 to 0.96$)$ & $<0.001$ & 0.96 (0.91 to 1.01$)$ & 0.095 & 1.05 (1.00 to 1.10$)$ & 0.055 \\
\hline & $\geq 75$ years & 0.97 (0.92 to 1.02$)$ & 0.250 & 1.02 (0.96 to 1.08 ) & 0.598 & 1.01 (0.95 to 1.06$)$ & 0.793 \\
\hline \multirow[t]{2}{*}{ Gender } & Male & 0.95 (0.91 to 1.01$)$ & 0.085 & 0.99 (0.94 to 1.05 ) & 0.726 & 1.03 (0.98 to 1.08 ) & 0.279 \\
\hline & Female & 0.92 (0.87 to 0.97$)$ & 0.004 & 0.97 (0.92 to 1.03 ) & 0.321 & 1.03 (0.98 to 1.09 ) & 0.254 \\
\hline \multirow[t]{2}{*}{ Education } & $<10$ years & 0.94 (0.89 to 0.99$)$ & 0.022 & 0.98 (0.92 to 1.04$)$ & 0.462 & 1.02 (0.96 to 1.08$)$ & 0.499 \\
\hline & $\geq 10$ years & 0.93 (0.89 to 0.98$)$ & 0.007 & 0.97 (0.93 to 1.02 ) & 0.289 & 1.04 (1.00 to 1.10$)$ & 0.070 \\
\hline \multirow[t]{2}{*}{ Equivalent income } & Low & 0.94 (0.89 to 0.98$)$ & 0.003 & 0.99 (0.95 to 1.04$)$ & 0.647 & 1.03 (0.99 to 1.08$)$ & 0.157 \\
\hline & High & $0.94(0.88$ to 1.00$)$ & 0.063 & 0.95 (0.89 to 1.02$)$ & 0.172 & 1.04 (0.97 to 1.11$)$ & 0.267 \\
\hline
\end{tabular}

*Estimation per 10 percentage points.

†Adjusted for age, gender, living arrangement, marital status, education, equivalent income, self-rated health, present illness and community-level covariates (urbanisation, ageing rate, and rate of low-level education). 
community-level civic participation and low frailty onset was broadly similar and showed the same direction in all strata. Previous studies have shown the association of low individual education and income with frailty, ${ }^{40}{ }^{41}$ suggesting a socioeconomic disparity of frailty. In our study, rich community-level civic participation had protective effects on frailty regardless of individual socioeconomic status; thus, fostering communitylevel civic participation could be key to addressing health disparities among older adults. Meanwhile, in the stratified analysis by age, the associations were in the same direction for both young-old adults and old-old adults, but the effect size was somewhat smaller among individuals aged $\geq 75$ years; the effects of social-environmental factors might vary with increasing age. As the physical function decline tends to be more accentuated in old-old adults than in young-old adults, ${ }^{42}$ for old-old adults, community-level civic participation might not be sufficiently effective and may require individual interventions alongside the fostering of community social capital.

Although this study provided pertinent insights regarding social-environmental factors for frailty prevention, there were several limitations. First, the social capital measurement was based on a self-administered questionnaire, denoting potential response measurement biases; social desirability bias may artificially affect the assessment of social capital, ${ }^{43}$ causing the overestimation of social capital. Second, the JAGES used a slightly modified version of the KCL, and slightly different versions were used in the baseline and follow-up surveys, which could have caused errors in frailty measurements. However, because only robust participants at baseline were followed, we were able to examine their frailty onset. Besides, our sensitivity analysis showed almost the same evidence to the main results. Thus, the effects of measurement error could be small. Third, considering the reversible nature of frailty, ${ }^{5}$ we cannot account for the changes in the frailty status during the follow-up period. Further examinations that consider recovery from frailty are necessary. Fourth, although this was a prospective longitudinal study, the nature of the observational study was unable to clarify causality due to unmeasured confounders. However, we have tried to adjust for major confounding variables on the individuals and communities. Finally, the geographical scale of our community unit (school districts) may be somewhat large for the

\section{What is already known on this subject}

- Communities rich in social capital may have protective effects on various health outcomes for older adults.

- However, evidence on the effects of community-level social capital on frailty remains unclear. Moreover, no prior research on the topic has conducted a longitudinal analysis.

\section{What this study adds}

- This longitudinal study revealed that communities with rich social capital, particularly high civic participation, could prevent frailty onset among older adults, regardless of individual socioeconomic status.

- Fostering civic participation in communities, including social activities, is of great importance when considering population-based approaches to frailty prevention in older adults. neighbourhood units. However, in Japan, school districts represent an area where older adults can easily travel on foot/bicycle and community organisations conduct their activities; thus, we believe that using school districts is meaningful for understanding the community characteristics.

\section{CONCLUSIONS}

This multilevel longitudinal study found that higher community civic participation was associated with lower frailty onset among older adults. Fostering social capital through promoting civic participation such as social activities in the community could help prevent frailty among older adults.

\section{Author affiliations \\ 'Department of Social Science, Research Institute, National Center for Geriatrics and Gerontology, Obu, Aichi, Japan \\ ${ }^{2}$ Department of Public Health, Nagoya City University Graduate School of Medical Sciences and Medical School, Nagoya, Aichi, Japan \\ ${ }^{3}$ Department of Health and Nutrition, Tokai Gakuen University, Nagoya, Aichi, Japan ${ }^{4}$ Department of Rehabilitation and Care, Seijoh University, Tokai, Aichi, Japan ${ }^{5}$ Department of Frailty Research, Research Institute, National Center for Geriatrics and Gerontology, Obu, Aichi, Japan \\ ${ }^{6}$ Department of Social Preventive Medical Sciences, Center for Preventive Medical Sciences, Chiba University, Chiba, Japan \\ ${ }^{7}$ Faculty of Social Welfare, Nihon Fukushi University, Chita-gun, Aichi, Japan ${ }^{8}$ Department of Gerontological Evaluation, Research Institute, National Center for Geriatrics and Gerontology, Obu, Aichi, Japan}

Acknowledgements We wish to express our sincere thanks to the staff in the surveyed municipalities for their contributions. We also thank the members of the Japan Gerontological Evaluation Study.

Contributors TN conceptualised and designed the study, analysed the data and drafted and revised the manuscript. CM, TH, RW, MS and MK helped to develop the study concept, interpret the results and reviewed and critically revised the manuscript. KK, the principal investigator of the JAGES project, helped to develop the study concept, participated in data collection and study design, and reviewed and critically revised the manuscript. TS helped to develop the study concept, interpret the results and reviewed and critically revised the manuscript. All authors approved submission of the final manuscript.

Funding This work was supported by Japan Society for the Promotion of Science (JSPS), KAKENHI Grant Numbers (17K04306, 19K24277, 21 K17322). The JAGES is supported by MEXT (Ministry of Education, Culture, Sports, Science and Technology of Japan)-Supported Program for the Strategic Research Foundation at Private Universities (2009-2013), JSPS (Japan Society for the Promotion of Science) KAKENHI Grant Numbers (JP18390200, JP22330172, JP22390400, JP23243070, JP23590786, JP23790710, JP24390469, JP24530698, JP24683018, JP25253052, JP25870573, JP25870881, JP26285138, JP26882010, JP15H01972), Health Labour Sciences Research Grants (H22-Choju-Shitei-008, H24-Junkanki-Ippan-007, H24-Chikyukibo-Ippan-009, H24-Choju-Wakate-009, H25-Kenki-Wakate-015, H25-Choju-Ippan-003, H26-Irryo-Shitei-003 [Fukkou], H26-Choju-Ippan-006, H27-Ninchisyou-Ippan-001, H28-Choju-Ippan-002, H28-Ninchisho-Ippan-002, H30Kenki-Ippan-006, H30-Junkankitou-Ippan-004), Japan Agency for Medical Research and Development (AMED) (JP17dk0110017, JP18dk0110027, JP18ls0110002, JP18le0110009, JP19dk0110034), the Research Funding for Longevity Sciences from the National Centre for Geriatrics and Gerontology (24-17, 24-23, 29-42, 30-22, 20-40, 21-17, 21-20), and the Open Innovation Platform with Enterprises, and Research Institute and Academia (OPEEA, JPMJOP1831) from the Japan Science and Technology Agency.

Disclaimer The funding sources had no role in the study design, data collection and analysis, decision to publish, or preparation of the manuscript.

Competing interests None declared.

\section{Patient consent for publication Not required.}

Ethics approval This study was reviewed and approved by the ethics committees at the University of Tokyo (No. 10555), Nihon Fukushi University (No. 13-14), National Centre for Geriatrics and Gerontology (No. 992), and Chiba University (No. 1777 and 2493). The mailed questionnaire was accompanied by a study explanation; participants who returned the completed questionnaire were considered to have provided informed consent. All our procedures conformed to the Declaration of Helsinki.

Provenance and peer review Not commissioned; externally peer reviewed. 
Data availability statement Data may be obtained from a third party and are not publicly available. For the JAGES, all inquiries are to be addressed to the data management committee via the following email: dataadmin.ml@jages.net. All JAGES datasets have ethical or legal restrictions for being placed in public repositories owing to the existence of sensitive information about the human participants.

Supplemental material This content has been supplied by the author(s). It has not been vetted by BMJ Publishing Group Limited (BMJ) and may not have been peer-reviewed. Any opinions or recommendations discussed are solely those of the author(s) and are not endorsed by BMJ. BMJ disclaims all liability and responsibility arising from any reliance placed on the content. Where the content includes any translated material, BMJ does not warrant the accuracy and reliability of the translations (including but not limited to local regulations, clinical guidelines, terminology, drug names and drug dosages), and is not responsible for any error and/or omissions arising from translation and adaptation or otherwise.

Open access This is an open access article distributed in accordance with the Creative Commons Attribution Non Commercial (CC BY-NC 4.0) license, which permits others to distribute, remix, adapt, build upon this work non-commercially, and license their derivative works on different terms, provided the original work is properly cited, appropriate credit is given, any changes made indicated, and the use is non-commercial. See: http://creativecommons.org/licenses/by-nc/4.0/.

ORCID iD

Taiji Noguchi http://orcid.org/0000-0001-9165-5501

\section{REFERENCES}

1 United Nations Department of Economic and Social Affairs. (DESA)/population division. World population prospects, 2019

2 Arai H, Ouchi Y, Toba K, et al. Japan as the front-runner of super-aged societies: perspectives from medicine and medical care in Japan. Geriatr Gerontol Int 2015;15:673-87.

3 Muramatsu N, Akiyama H. Japan: super-aging Society preparing for the future. Gerontologist 2011;51:425-32.

4 Clegg A, Young J, lliffe S, et al. Frailty in elderly people. The Lancet 2013;381:752-62.

5 Abellan van Kan G, Rolland Y, Bergman H, et al. The I.A.N.A task force on frailty assessment of older people in clinical practice. J Nutr Health Aging 2008;12:29-37.

6 Kojima G. Frailty as a predictor of nursing home placement among communitydwelling older adults: a systematic review and meta-analysis. J Geriatr Phys Ther 2018;41:42-8.

7 Kojima G. Frailty as a predictor of hospitalisation among community-dwelling older people: a systematic review and meta-analysis. J Epidemiol Community Health 2016;70:722-9.

8 Kojima G. Frailty as a predictor of disabilities among community-dwelling older people: a systematic review and meta-analysis. Disabil Rehabil 2017;39:1897-908.

9 Kojima G, Taniguchi Y, lliffe S, et al. Frailty as a predictor of Alzheimer disease, vascular dementia, and all dementia among community-dwelling older people: a systematic review and meta-analysis. J Am Med Dir Assoc 2016;17:881-8.

10 World Health Organization. World report on ageing and health 2015. Geneva, Switzerland, 2015.

11 De Witte N, Gobbens R, De Donder L, et al. The comprehensive frailty assessment instrument: development, validity and reliability. Geriatr Nurs 2013;34:274-81.

12 Gobbens RJ, Luijkx KG, Wijnen-Sponselee MT, et al. Toward a conceptual definition of frail community dwelling older people. Nurs Outlook 2010;58:76-86.

13 Markle-Reid M, Browne G. Conceptualizations of frailty in relation to older adults. J Adv Nurs 2003;44:58-68.

14 Gobbens RJJ, van Assen MALM, Luijkx KG, et al. The Tilburg frailty indicator: psychometric properties. J Am Med Dir Assoc 2010;11:344-55.

15 World Health Organization. WHO clinical consortium on healthy ageing: topic focus: frailty and intrinsic capacity: report of consortium meeting, 1-2 December 2016 in Geneva, Switzerland, 2017

16 Murayama H, Fujiwara Y, Kawachi I. Social capital and health: a review of prospective multilevel studies. J Epidemio/ 2012;22:179-87.

17 Putnam RD, Leonardi R, Nanetti R. Making democracy work: civic traditions in modern Italy. Princeton University Press, 1993.
18 Saito M, Kondo N, Aida J, et al. Development of an instrument for community-level health related social capital among Japanese older people: the JAGES project. J Epidemiol 2017;27:221-7.

19 Coleman J. Foundations of social theory. Massachusetts: Harvard University Press, 1990.

20 Kawachi I, Kennedy BP, Lochner K, et al. Social capital, income inequality, and mortality. Am J Public Health 1997;87:1491-8.

21 Islam MK, Merlo J, Kawachi I, et al. Social capital and health: does egalitarianism matter? A literature review. Int J Equity Health 2006;5:3.

22 Kawachi I, Berkman LF. Social epidemiology. Social capital, social cohesion, and health. Oxford University Press, 2015.

23 Islam MK, Gerdtham U-G, Gullberg B, et al. Social capital externalities and mortality in Sweden. Econ Hum Biol 2008;6:19-42.

24 Inoue S, Yorifuji T, Takao S, et al. Social cohesion and mortality: a survival analysis of older adults in Japan. Am J Public Health 2013;103:e60-6.

25 Aida J, Kondo K, Kawachi I, et al. Does social capital affect the incidence of functional disability in older Japanese? A prospective population-based cohort study. J Epidemiol Community Health 2013;67:42-7.

26 Noguchi T, Kondo K, Saito M, et al. Community social capital and the onset of functional disability among older adults in Japan: a multilevel longitudinal study using Japan Gerontological evaluation study (JAGES) data. BMJ Open 2019;9:e029279.

27 Ye B, Gao J, Fu H. Associations between lifestyle, physical and social environments and frailty among Chinese older people: a multilevel analysis. BMC Geriatr 2018;18:314.

28 Sato K, Ikeda T, Watanabe R, et al. Intensity of community-based programs by longterm care insurers and the likelihood of frailty: multilevel analysis of older Japanese adults. Soc Sci Med 2020;245:112701.

29 Kondo K. Progress in aging epidemiology in Japan: the JAGES project. J Epidemiol 2016;26:331-6.

30 Arai H, Satake S. English translation of the Kihon checklist. Geriatr Gerontol Int 2015:15:518-9.

31 Satake S, Senda K, Hong Y-J, et al. Validity of the Kihon checklist for assessing frailty status. Geriatr Gerontol Int 2016;16:709-15.

32 Satake S, Shimokata H, Senda K, et al. Validity of total Kihon checklist score for predicting the incidence of 3-year dependency and mortality in a community-dwelling older population. J Am Med Dir Assoc 2017;18:552.e1-6.

33 Harpham T. The measurement of community social capital through surveys. In: Kawachi I, Subramanian SV, Kim D, eds. New York, NY: Springer New York, 2008: 51-62.

34 Aida J, Kondo K, Hirai $\mathrm{H}$, et al. Assessing the association between all-cause mortality and multiple aspects of individual social capital among the older Japanese. BMC Public Health 2011;11:499.

35 Merlo J, Chaix B, Ohlsson H, et al. A brief conceptual tutorial of multilevel analysis in social epidemiology: using measures of clustering in multilevel logistic regression to investigate contextual phenomena. J Epidemiol Community Health 2006;60:290-7.

36 White IR, Royston P, Wood AM. Multiple imputation using chained equations: issues and guidance for practice. Stat Med 2011;30:377-99.

37 Koyama S, Aida J, Saito M, et al. Community social capital and tooth loss in Japanese older people: a longitudinal cohort study. BMJ Open 2016;6:e010768.

38 Yamaguchi M, Inoue Y, Shinozaki T, et al. Community social capital and depressive symptoms among older people in Japan: a multilevel longitudinal study. J Epidemiol 2019;29:363-9.

39 Hoogendijk EO, Afilalo J, Ensrud KE, et al. Frailty: implications for clinical practice and public health. Lancet 2019;394:1365-75.

40 Murayama H, Kobayashi E, Okamoto $\mathrm{S}$, et al. National prevalence of frailty in the older Japanese population: findings from a nationally representative survey. Arch Gerontol Geriatr 2020;91:104220.

41 Ikeda T, Tsuboya T, Aida J, et al. Income and education are associated with transitions in health status among community-dwelling older people in Japan: the JAGES cohort study. Fam Pract 2019;36:713-22.

42 Suzuki T, Nishita Y, Jeong S, et al. Are Japanese older adults rejuvenating? changes in health-related measures among older community dwellers in the last decade. Rejuvenation Res 2021;24:37-48.

43 Heitmann BL. Social desirability bias in dietary self-report may compromise the validity of dietary intake measures. Implications for diet disease relationships. Int J Epidemiol $1996 ; 25: 222-5$. 